\title{
Review of cryptogenic fibrosing alveolitis, including current treatment guidelines
}

\author{
Stephen C Bourke, Howell Clague
}

Cryptogenic fibrosing alveolitis (CFA), known as idiopathic pulmonary fibrosis in the USA, is characterised by inflammation and fibrosis of the alveoli and interstitium of the lungs, favouring the subpleural and basal regions. By definition the diagnosis demands that all known causes of pulmonary fibrosis have been excluded. It is now clear that the CFA population is comprised of a heterogeneous group, with varying clinical, radiological and histological features, which in turn may be used to predict response to treatment and prognosis. The British Thoracic Society has recently produced guidelines on the investigation and management of diffuse parenchymal lung disease, including CFA. ${ }^{1}$

\section{Epidemiology}

Epidemiological data on CFA is limited. A population based registry of patients with interstitial lung disease was established in Bernalillo County, New Mexico, between 1 October 1988 and 30 September 1990. ${ }^{2}$ The incidence of idiopathic pulmonary fibrosis (excluding undefined pulmonary fibrosis) for men and women was 10.7 and 7.4/100 000/ year respectively, and increased dramatically with age, reaching 102/100 000/year in men $\geqslant 75$ years. Overall prevalence was 16.7/ 100000 (reaching 28/100 000 including undefined pulmonary fibrosis); in contrast the prevalence in the UK has been estimated at $6 / 100000 .^{3}$ Population differences and more strict diagnostic criteria in the UK study may explain the difference.

The British Thoracic Society conducted a prospective observational study involving 588 newly diagnosed cases of CFA between 1 December 1990 and 31 November 1992. The mean age at presentation was 67.4 years, with a male:female ratio of $1.7: 1 .^{4}$ An earlier retrospective analysis of 220 cases in a tertiary centre UK study reported a 2:1 male preponderance, with an earlier mean age of onset of symptoms of 55 years (perhaps reflecting referral bias), and median survival of 40 months and 77.5 months for men and women respectively. ${ }^{5}$ Overall mean survival in the British Thoracic Society study was three years, ${ }^{4}$ compared with four to five years previously reported (tertiary centres)..$^{5-7}$

In England and Wales the mortality doubled from 336 in 1979 to 702 in 1988 . The official figures may underestimate deaths by half. Mortality rates rise sharply with age (7.8 times higher $\geqslant 75$ years than $45-64$ years), male sex (odds ratio 2.24) and in industrialised areas (odds ratio $1.25)^{.8} \mathrm{~A}$ similar increase in mortality has been reported in many other countries. ${ }^{9}$

\section{Aetiology}

CFA is more common in men and in areas of the UK with a strong background in manufacturing industry. ${ }^{8}$ Exposure to dusts not yet recognised as causing pneumoconiosis may be involved. Occupational exposures to metal dust (specifically steel, brass, and lead) or wood dust (specifically pine) are independent risk factors for the development of CFA, possibly accounting for $20 \%$ of cases. ${ }^{3}{ }^{10}$ There is an association with exposure to wood smoke and working with cattle, ${ }^{3}$ smoking, ${ }^{10-12}$ laundry workers, barbers, beauticians, and painters. ${ }^{12} \mathrm{~A}$ recent study reported a significant association with farming, hairdressing, exposure to metal dust, raising birds, stone cutting, and exposure to animal and vegetable dusts. ${ }^{13}$ A possible aetiological role for solvents has been proposed. ${ }^{14}$ An association with antidepressant therapy (imipramine, dothiepin, and mianserin), possibly accounting for $10 \%$ of cases, has been reported recently. ${ }^{15}$

Patients often give a history of a viral-like illness preceding the onset of their symptoms, although causation remains unproved. It is possible that viruses may act as an initial trigger factor, or a primary environmental injury may be potentiated by viral replication within the injured tissue. This area has been thoroughly reviewed by Egan et al. ${ }^{16}$ Current evidence suggests that hepatitis $C$ virus ${ }^{16}$ and adenovirus ${ }^{17}{ }^{18}$ are unlikely to be aetiologically involved. There is stronger evidence for a possible role for Epstein-Barr virus (EBV). Vergnon et al reported an association between CFA and serological evidence of EBV infection. ${ }^{19}$ Egan et al demonstrated evidence of replicating EBV by immunohistochemical techniques, ${ }^{20}$ and EBV DNA by nested polymerase chain reaction (PCR) ${ }^{21}$ in lung tissue from patients with idiopathic pulmonary fibrosis compared with controls. However another group failed to confirm these findings using PCR amplification. ${ }^{22}$

Patients with CFA, confirmed to have no evidence of rheumatoid arthritis or a connec-

Box 1: Epidemiology
- UK prevalence: $6 / 100000$
- Male to female incidence ratio $1.7: 1$
- Mean age of presentation: 67 years
- Mean life expectancy: three years
- Male to female life expectancy ratio: $1: 2$
- Mortality, and by implication incidence,
is increasing
- Both incidence and mortality rates rise
sharply with age




\section{Box 2: Aetiology}

- Possible aetiological factors include: metal dust (steel, brass, lead); wood dust (pine); wood smoke; smoking

- Many other dusts and occupational associations have been implicated

- Rare familial forms (autosomal dominant) are recognised

- Role of viral infections not established

tive tissue disorder, not infrequently have a positive rheumatoid factor $(19 \%)$ or antinuclear factor $(26 \%),{ }^{4}$ suggesting an immunological derangement may be involved.

A familial form of CFA, probably with autosomal dominant inheritance, has been reported, ${ }^{23}$ but is very rare. It is likely that CFA represents a stereotypic response in the lungs of susceptible individuals to a variety of environmental factors.

\section{Pathology}

CFA may be classified histologically into three principal groups, based on the pattern and degree of fibrosis and inflammatory alveolitis: usual interstitial pneumonia (UIP), desquamative interstitial pneumonia (DIP), and nonspecific interstitial pneumonia (NSIP).

UIP, the most common pattern, is characterised by a heterogeneous appearance with alternating zones of normal lung, chronic inflammatory alveolitis (predominantly lymphocytes, plasma cells, and histiocytes) and fibrosis, often with areas of end stage honeycomb change. Lung architecture is destroyed in affected zones. $^{24}$

DIP is less variegated. Alveolar septa are thickened by connective tissue and inflammatory infiltrate (lymphocytes, plasma cells, and occasional eosinophils), with little fibrosis. Type II pneumocyte hyperplasia and intraalveolar pigmented macrophages are prominent. Lung architecture is better preserved. ${ }^{24}$

NSIP is characterised by varying proportions of interstitial inflammatory infiltrate and fibrosis, differing from UIP in its homogenous distribution and temporal uniformity - that is, all affected areas exhibit equal proportions of inflammatory and fibrotic elements, ${ }^{25}$ suggestive of a reaction to a single insult.

The present classification of the interstitial pneumonias of unknown aetiology also includes respiratory bronchiolitis associated interstitial lung disease (RBILD) and acute interstitial pneumonia (AIP) in addition to UIP, DIP, and NSIP. RBILD is histologically similar to DIP however it occurs virtually exclusively in smokers. It probably represents the same underlying disease process upon which smoking has had a major influence. The histological features of AIP resemble a subacute/organising form of acute respiratory distress syndrome. AIP is a rare and rapidly progressive disorder. Hamman and Rich are often credited with the earliest description of CFA (1944), ${ }^{26}$ however the four patients

\section{Box 3: Pathology}

UIP

- Mean survival 2.8-5.6 years

- Response to steroids $12 \%$

- Spontaneous improvement does not occur

\section{DIP}

- Mean survival 12.4-14.0 years

- Response to steroids $62 \%$

- Spontaneous improvement $22 \%$

NSIP

- Survival (mean 14 years) and therapeutic response similar to DIP

described died soon after presentation (4-24 weeks) and probably suffered from AIP.

Histological appearance predicts prognosis and response to treatment, therefore biopsy may be indicated even if the clinical diagnosis is secure. Carrington et al conducted a longitudinal prospective study involving 93 patients followed for up to 22 years. ${ }^{24}$ Compared with UIP, the group with DIP where significantly younger (42.3 v 50.9 years), with better survival (mean $12.2 v 5.6$ years) and response to treatment $(61.5 \%$ v $11.5 \%)$. Interestingly in the untreated group spontaneous improvement was seen in $21.9 \%$ of patients with DIP, but none with UIP. ${ }^{24}$ A more recent retrospective analysis reported mean survival for DIP of 14 years, and UIP of 2.8 years. $^{27}$

Patients with UIP at presentation are approximately 10 years older, yet with a similar duration of illness, severity of symptoms, and functional defect as those with DIP. This observation in conjunction with the data above suggests we are dealing with separate disease entities, as opposed to progression of the same underlying disease process.

\section{Clinical features}

The majority of patients describe a gradual onset of progressive exertional dyspnoea ( $~ 90$ $\%$ ) and chronic cough ( $74 \%)$, either dry or productive (smoking common). ${ }^{4} \mathrm{Up}$ to $36 \%$ of patients present with breathlessness at rest or on minimal exertion, while about $5 \%$ are asymptomatic. ${ }^{4}$ Arthralgia or arthritis is seen in $19 \%$ of cases, more commonly in women (after excluding rheumatoid arthritis or connective tissue disorders). ${ }^{4}$ Symptoms may be preceded by a viral-like illness. ${ }^{28}$ Fatigue and weight loss are common. Almost half of patients give a history of some dust exposure, and $76 \%$ are current or ex-smokers. ${ }^{4}$

Virtually all patients have bibasal dry "Velcro" crackles, initially late inspiratory, later becoming paninspiratory. Finger clubbing is seen in $50 \%-66 \%,{ }^{4}$ but hypertrophic pulmonary osteoarthropathy is rare. Patients are typically tachypnoeic, and may be cyanosed on exertion or at rest, depending on the severity of disease. In the advanced stages features of pulmonary hypertension and cor pulmonale may become evident. ${ }^{28}$ Type I respiratory failure, 


\section{Box 4: Clinical features}

- Progressive exertional dyspnoea: $90 \%$

- Chronic cough: $74 \%$

- Arthralgia/arthritis: $19 \%$

- Dry "Velcro" crackles

- Clubbing: $50 \%-60 \%$

\section{Box 5: Lung function}

- Intrapulmonary restrictive defect or isolated fall in TLCO

- Vital capacity and TLCO are most appropriate indicators of change

- DPTA clearance predicts likelihood of disease progression in non-smokers

with preserved ventilatory drive, is characteristic. The development of type II respiratory failure often heralds the terminal phase of the disease process.

\section{Lung function}

CFA classically produces an intrapulmonary restrictive defect. Forced expiratory volume in one second and forced vital capacity (FVC) are reduced with a preserved or increased ratio. Lung volumes and carbon monoxide transfer factor (TLCO) are also reduced..$^{29}{ }^{30}$ However lung function parameters may be relatively normal in mild disease, with the earliest change being a reduction in TLCO. There is a high incidence of cigarette smoking, resulting in coexistent emphysema in many patients, producing counteracting abnormalities. This may result in relative normalisation of lung volumes and flows in a very breathless patient, however the TLCO will be low. ${ }^{30}$ Changes in FVC and TLCO after one year of treatment appear to be useful predictors of survival. ${ }^{32}$ While others have found contradictory results, ${ }^{33}$ with regard to lung function monitoring in CFA, $(\mathrm{F}) \mathrm{VC}$ and TLCO remain the simplest and most appropriate indicators of change. Although advocated by some, current evidence does not support the routine use of exercise testing. ${ }^{1}$

Clearance of aerosolised technetium labelled diethylenetriamine penta-acetate ${ }^{99 \mathrm{~m}} \mathrm{Tc}-$ DPTA) from the lung is a sensitive measure of epithelial permeability, and therefore of inflammation in the lung. In CFA normal clearance predicts stable disease, while persistently raised clearance predicts disease progression, ${ }^{34}$ and may justify early instigation of treatment before symptomatic deterioration, although further clinical studies are required. Clearance is also increased in smokers, limiting the clinical application of this technique. Its role in CFA has yet to be established.

\section{Radiology}

Features seen on chest radiography include reticular shadowing which predominantly affects the lower zones and subpleural regions, obscuring the diaphragm and cardiac border. Areas of ground glass shadowing (increase in attenuation without obscuring vessels) may be discernible. In the later stages the reticular shadowing becomes coarser, and honeycombing may be present. Lung volumes are typically reduced, unless coexistent emphysema is present. Notably the chest radiograph is normal at presentation in up to $16 \%$ of patients. $^{3536}$

High resolution computed tomography (HRCT) has revolutionised the investigation of CFA, providing both diagnostic and prognostic information (figs 1-3). Reticular densities or frank honeycombing correlate strongly with fibrosis on biopsy, ${ }^{37} 38$ and ground glass shadowing correlates with areas of active inflammation $^{38-40}$ or fine fibrosis (below the resolution of HRCT), which may be distinguished by the presence of traction bronchioliectasis. ${ }^{40}$ The pattern may be virtually pathognomic. With experienced radiologists the diagnostic accuracy of HRCT is about $88 \%{ }^{41}{ }^{42}$ While more sensitive and specific than chest radiography, a normal HRCT scan does not exclude clinically significant disease. ${ }^{36}$

A predominantly ground glass shadowing pattern correlates with improved prognosis and response to therapy, ${ }^{43}$ nevertheless biopsy may still be considered, as prognosis depends not only on extent of ground glass shadowing and reticular shadowing, but also underlying histology. In UIP ground glass shadowing usually increases in extent or progresses to fibrosis despite treatment, while in DIP ground glass shadowing usually remains stable or improves with therapy. ${ }^{44}$ A predominantly reticular pattern correlates very strongly with a predominantly fibrotic histology, ${ }^{42}$ poor response to treatment and prognosis. Biopsy is not necessary to determine prognosis. When biopsy is indicated, the HRCT scan also serves as a guide to the most appropriate site. ${ }^{40}$

\section{Diagnosis}

In clinical practice we are usually confronted by a breathless patient with reticulonodular shadowing on chest radiography. The classical symptoms and signs are documented above. It is important to note the duration and rate of progression of symptoms, any organic or inorganic dust exposure (especially occupational), and relevant past and present drug exposure. Symptoms or signs suggestive of an underlying connective tissue disorder should be investigated. The current chest radiograph should be viewed with previous films. Lung function tests may reveal an intrapulmonary restrictive defect or simply an isolated fall in TLCO. Relevant blood tests include autoantibody screen, rheumatoid factor, and avian precipitins. In the British Thoracic Society study the diagnosis was made on clinical grounds alone in $60 \%$ of cases. ${ }^{4}$

A HRCT scan is the next investigation of choice to confirm the diagnosis and determine prognosis. ${ }^{45}$ Transbronchial biopsy provides inadequate samples to diagnose CFA, but may be indicated to exclude bronchocentric conditions such as sarcoidosis, infection, or alveolar cell carcinoma. Bronchoalveolar lavage is useful in excluding infection and malignancy, 


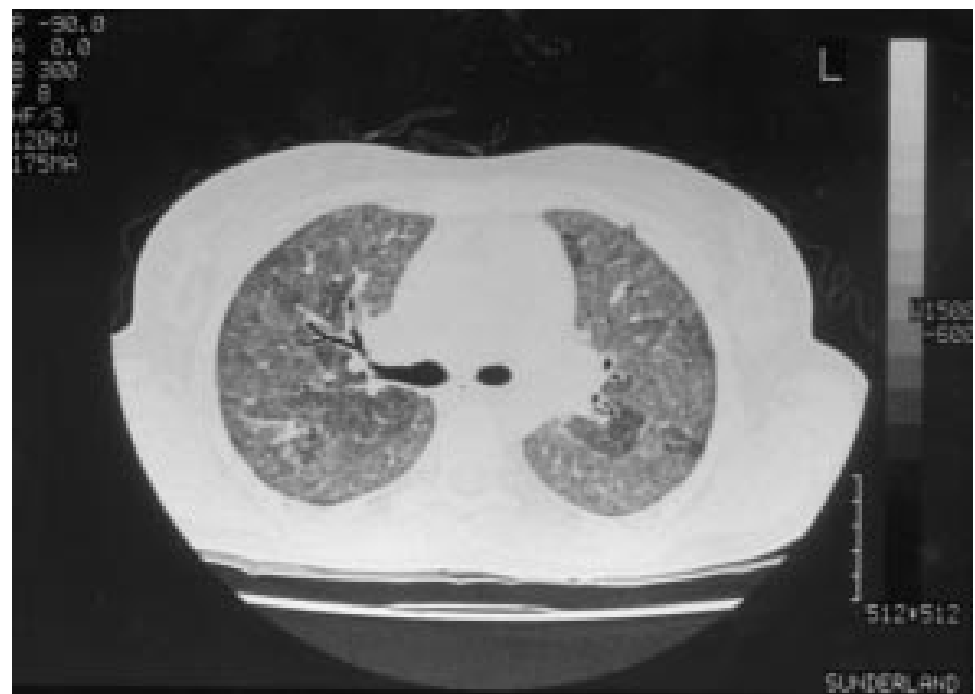

Figure 1 Diffuse "ground glass" opacification is the hallmark of DIP. Macrophages fill the alveolar airspaces, with only minimal fibrosis. Note the major airways appear much "blacker" than lung parenchyma. Small areas of less involved lung have intermediate density.

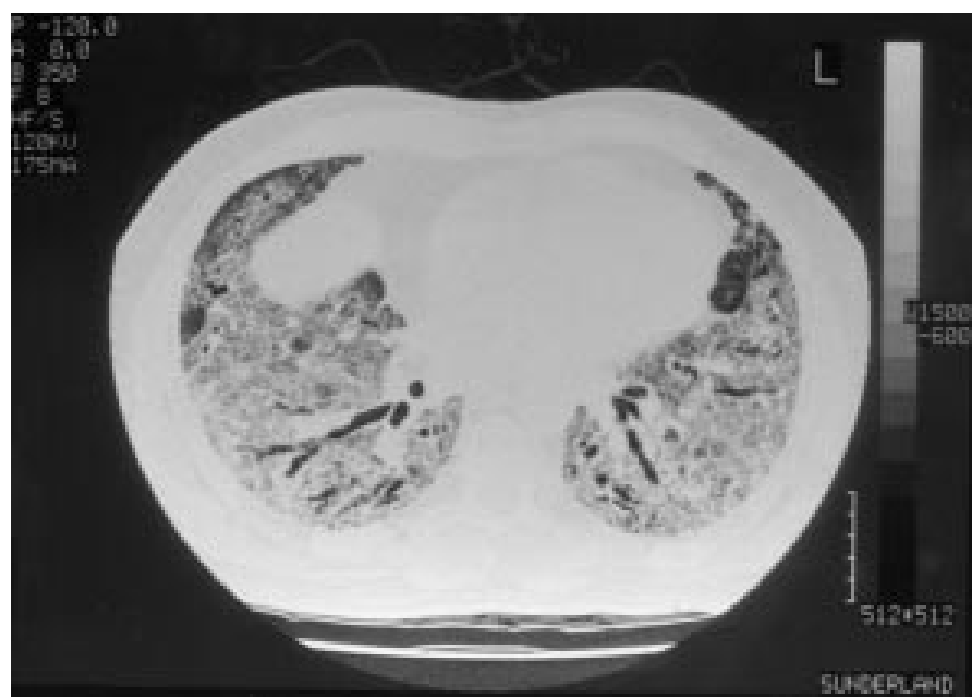

Figure 2 Diffuse "ground glass" or airspace opacification with more marked interstitial fibrosis, early cyst formation, and secondary traction bronchiectasis. This appearance represents the transition between the typical pattern of DIP and UIP.

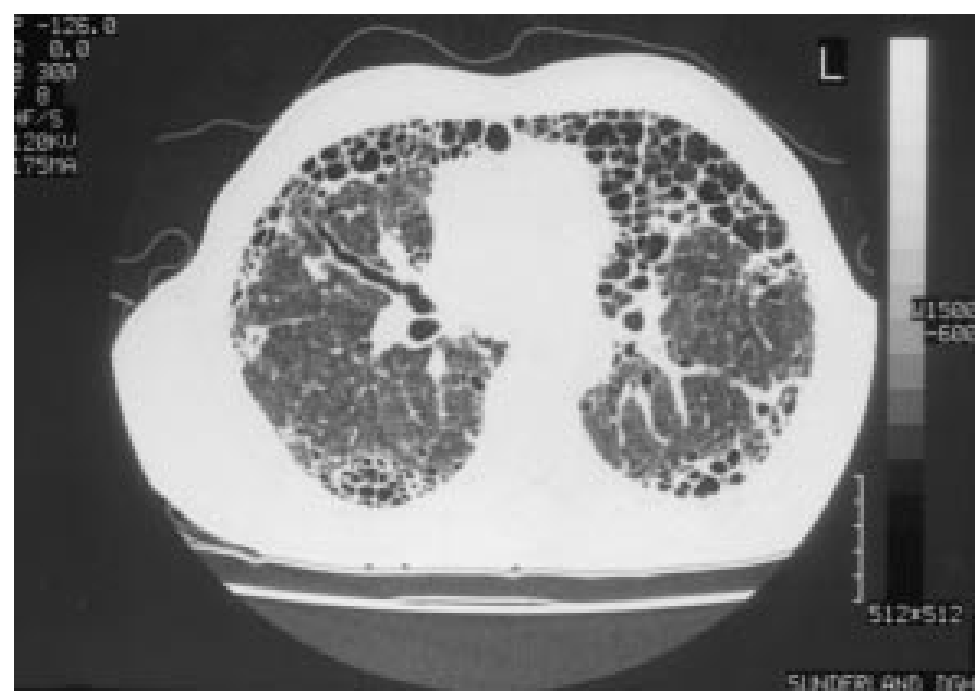

Figure 3 Confluent peripheral cyst formation, interstitial fibrosis, and traction bronchiectasis represents the typical appearance of UIP, progressing to end stage lung disease. Note the absence of airspace opacification. and possibly predicting response to steroid therapy $^{46}$ (lymphocytic: good response, neutrophilic: poor response, but not necessarily to other immunosuppressants). Open lung biopsy remains the gold standard for diagnosis and should be considered if there is any doubt. Even when the diagnosis is established, if the HRCT reveals areas of predominantly ground glass shadowing, biopsy provides additional prognostic information. ${ }^{44}$ Video assisted thoracoscopic biopsy minimises morbidity without compromising diagnostic rate. The decision to proceed to biopsy is also influenced by the patient's age, performance status, and comorbidity.

\section{Treatment}

Therapeutic trials in CFA have often used different diagnostic criteria. Conformation of the diagnosis by open lung biopsy and determination of the histological subgroup has not always been sought. Difficulty recruiting sufficient patient numbers has critically limited the power to provide a definitive answer. The only randomised controlled trials have been small and assessed second line agents (azathioprine, cyclophosphamide).

\section{CORTICOSTEROIDS}

A randomised placebo controlled trial assessing response to corticosteroids has never been performed, and would now be regarded as unethical. An objective improvement with corticosteroids has been reported in 16\%-30\% of patients with CFA, ${ }^{67}{ }^{47}$ and over $60 \%$ in the subgroup with DIP. ${ }^{24}$ Other features associated with a favourable response include female gender, ${ }^{6}$ younger age at presentation, ${ }^{47}$ less dyspnoea, ${ }^{46}$ predominantly ground glass shadowing on HRCT, ${ }^{42}$ and increased cellularity of the biopsy. ${ }^{624}$ Any benefits (objective improvement/clinical stability) must be weighed against the side effects of long term corticosteroid use. Assessment for osteoporosis prophylaxis is now mandatory.

\section{AZATHIOPRINE}

Azathioprine and high dose prednisolone has been compared with high dose prednisolone alone in a double blind randomised placebo controlled trial involving 27 patients. ${ }^{48}$ Adjusting for age, there was a significant survival advantage with the azathioprine regimen $(57 \%$ $v 23 \%$ at nine years), and a non-significant trend for better lung function. Azathioprine was well tolerated. This has lead to the current British Thoracic Society recommendation for dual therapy at the outset.

\section{Box 6: High resolution computed tomography}

- High diagnostic accuracy

- Predicts prognosis

- May avoid need for biopsy, especially if predominantly reticular shadowing

- Acts as a guide to ideal biopsy site 
CYCLOPHOSPHAMIDE

In the single randomised controlled trial assessing the response to cyclophosphamide, cyclophosphamide and low dose prednisolone was compared with high dose prednisolone in 43 patients. $^{49}$ There were different steroid doses used in each arm, therefore caution must be exercised in attributing results to the addition of cyclophosphamide alone. Furthermore the prednisolone only group had relatively worse lung function. At three years three of 21 patients in the cyclophosphamide/ prednisolone group had died compared with 10 of 22 in the prednisolone only group, however survival curves converged at 5-9 years. Looking at death or failure of first line treatment combined, there was a significant advantage for cyclophosphamide and prednisolone, however in subgroup analysis by lung function this advantage was only maintained for total lung capacity $60 \%-79 \%$. Adverse reactions (mainly haematological) were seen in $19 \%$ of those receiving cyclophosphamide.

OTHER AGENTS

Colchicine has been compared with high dose steroid in a randomised trial $(n=26) .{ }^{50}$ There was no significant difference in survival between the two groups, however there was a trend for better preservation of lung function and survival with fewer side effects in the colchicine group. There are some reports in the literature of a response to both cyclosporin and penicillamine.

CURRENT THERAPY: BRITISH THORACIC SOCIETY RECOMMENDATIONS

In very symptomatic or rapidly deteriorating patients treatment is often justifiably instigated immediately. In the rest the rate of disease progression should be assessed first over at least three months. ${ }^{1}$ Patient wishes and comorbidity will obviously influence the decision to start treatment.

The current recommended first line treatment is a combination of prednisolone (0.5 $\mathrm{mg} / \mathrm{kg}$ ) and azathioprine $(2-3 \mathrm{mg} / \mathrm{kg}) .{ }^{1}$ Patients should be assessed at one month. Response or stability should be followed by a slow tail of prednisolone to a maintenance dose of $10 \mathrm{mg}$ continued for one year, with further reductions subsequently considered. Deterioration (10-15\% fall in TLCO/VC) should lead to rapid reduction and cessation of steroid therapy. Cyclophosphamide $(1-2 \mathrm{mg} / \mathrm{kg})$ is an alternative if azathioprine is not tolerated, while if prednisolone is not tolerated single agent azathioprine or colchicine may be considered. If ground glass shadowing predominates single agent prednisolone is currently recommended as first line therapy.

\section{Transplantation}

Single lung transplantation is an option in selected patients with progressive disease despite medical therapy. Unfortunately patients with pulmonary fibrosis have the highest death rate on the waiting list for a donor organ due to the rapid rate of disease progression. This underlines the importance of early
Box 7: Good prognostic factors

- Clinical: young age, female, and response to steroids

- Radiological: predominantly ground glass shadowing

- Histological: predominantly cellular biopsy, DIP or NSIP histological subgroup

specialist referral and assessment for suitability for transplantation. Guidelines for referral include VC, total lung capacity $<60 \%$, resting hypoxia, secondary pulmonary hypertension, and progression on appropriate medical therapy. ${ }^{51}$ Survival after successful transplantation is about $50 \%$ at five years and is improving.

\section{Prognosis}

As stated earlier, mean survival in unselected patients is only three years, ${ }^{4}$ however there is a wide range. The combination of clinical, radiological, and histological (if sought) features together help to predict response to therapy and outcome, and can influence difficult management decisions.

The majority of deaths are directly related to CFA,${ }^{4-7}$ usually caused by respiratory failure, and respiratory infection not infrequently precipitates the final decompensation. Other CFA related deaths include lung cancer (accounting for up to $12.8 \%^{4-6}$ ) and pulmonary embolism. ${ }^{5}$ A significant number of deaths are caused by cardiovascular disease (older population, high incidence of smoking).

Unfortunately the response of many patients to currently available therapy is disappointing, and side effects are significant. New, more specific, and effective antifibrotic agents are urgently required.

The authors would like to thank Dr Peter Shepherd at Sunderland Royal Hospital for providing the radiology images and captions.

1 Cushley MJ, Davison AG, Du Bois RM, et al. The diagnosis, assessment, and treatment of diffuse parenchymal lung disease in adults. Thorax 1999;54(suppl 1).

2 Coultas DB, Zumwalt RE, Black WC, et al. The epidemiology of interstitial lung disease. F Respir Crit Care Med 1994; 150:967-72.

3 Scott J, Johnston I, Britton J. What causes cryptogenic fibrosing alveolitis? A case-control study of environmental exposure to dust. BMF 1990;301:1015-17.

4 Johnston IDA, Prescott RJ, Chalmers JC, et al. British Thoracic Society study of cryptogenic fibrosing alveolitis: current presentation and initial management. Thorax 1997; 52:38-44.

5 Turner-Warwick M, Burrows B, Johnston A. Cryptogenic

Turner-Warwick $M$, Burrows B, Johnston A. Cryptogenic
fibrosing alveolitis: clinical features and their influence on fibrosing alveolitis: clinical feature
survival. Thorax 1980;35:171-80.

6 Stack BRH, Choo-Kang YFJ, Heard BE. The prognosis of cryptogenic fibrosing alveolitis. Thorax 1972;27:535-42.

7 Tukiainen P, Taskinen E, Holsti P, et al. Prognosis of cryptogenic fibrosing alveolitis. Thorax 1983;38:349-55.

8 Johnston I, Britton J, Kinnear W, et al. Rising mortality from cryptogenic fibrosing alveolitis. BMF 1990;301:1017-21.

9 Hubbard R, Johnston I, Coultas DB, et al. Mortality rates from cryptogenic fibrosing alveolitis in seven countries. Tho$\operatorname{rax} 1996 ; 51: 711-16$

10 Hubbard R, Lewis S, Richards K, et al. Occupational exposure to metal or wood dust and aetiology of cryptogenic fibrosing alveolitis. Lancet 1996;347:284-9.

11 Baumgartner KB, Samet JM, Stidley CA, et al. Cigarette smoking as a risk factor for idiopathic pulmonary fibrosis. Am 7 Respir Crit Care Med 1997;155:242-8.

12 Iwai $\mathrm{K}$, Mori T, Yamada N, et al. Idiopathic pulmonary fibrosis: epidemiological approaches to occupational expofibrosis: epidemiological approaches to occupationa
sure. Am $\mathcal{F}$ Respir Crit Care Med 1994;150:670-5. 


\section{Questions (true or false; answers at end of paper)}

1. The mortality from cryptogenic fibrosing alveolitis:

(A) Increases with increasing age

(B) Is higher in women

(C) Is higher in industrial areas

(D) increased in recent years

2. Cryptogenic fibrosing alveolitis is linked with the following:

(A) Working with pine wood dust

(B) Infection with Epstein-Barr virus

(C) A familial inheritance

(D) Positive serological markers for connective tissue disease

3. The following are thought to be true about fibrosing alveolitis:

(A) A lung biopsy is of no help in predicting response to treatment

(B) Ground glass shadowing can sometimes undergo spontaneous improvement

(C) About three quarters of sufferers have a history of recent or past cigarette smoking

(D) Finger clubbing is relatively uncommon

4. The following best describe the clinical features of the cryptogenic form of the disease:

(A) A cough is the second most common symptom

(B) Arthralgia or arthritis is rare

(C) Late inspiratory bibasal "Velcro" crackles is a classical finding

(D) Hypertrophic pulmonary osteoarthropathy is rare

5. In the imaging of cryptogenic fibrosing alveolitis:

(A) The chest $x$ ray is always abnormal

(B) Computed tomography can provide sufficient diagnostic and prognostic information without the need for biopsy

(C) A predominantly reticular pattern correlates with an improved prognosis and response to treatment

(D) Clearance of ${ }^{99 \mathrm{~m}} \mathrm{Tc}$-DPTA from the lung may have a role in the early detection of disease in smokers

6. The following are true of the treatment of cryptogenic fibrosing alveolitis:

(A) There is a good evidence base that corticosteroids improve the long term outcome

(B) The current recommended treatment in the UK specifies a combination of azathioprine and prednisolone

(C) Cyclophosphamide is an alternative if azathioprine is poorly tolerated

(D) Lung transplantation should be considered early in the management of fibrosing alveolitis
13 Baumgartner KB, Samet JM, Coultas DB, et al. Occupational and environmental risk factors for idiopathic pulmonary fibrosis. Am 7 Epidemiol 1997;145:242.

14 Billings CG, Howard P. Hypothesis: exposure to solvents may cause fibrosing alveolitis. Eur Respir F 1994;7:1172-6.

15 Hubbard R, Venn A, Smith C, et al. Exposure to commonly prescribed drugs and the aetiology of cryptogenic fibrosing alveolitis: a case-control study. Am $\mathcal{F}$ Respir Crit Care Med 1998;157(3 pt 1):743-7.

16 Egan JJ, Woodcock AA, Stewart JP. Viruses and idiopathic pulmonary fibrosis. Eur Respir f 1997;10:1433-7.

17 Kuwano K, Nomoto Y, Kunitake R, et al. Detection of adenovirus E1A DNA in pulmonary fibrosis using nested polynmerase chain reaction. Eur Respir f 1997;10:1445-9.

18 Agusti C, Xaubet A, Ballester E, et al. Aerosolised ribivarin in patients with advanced cryptogenic fibrosing alveolitis: a pilot study. Thorax 1993;48:68-9.

19 Vergnon JM, Vincent M, De Thé G, et al. Cryptogenic fibrosing alveolitis and Epstein-Barr virus: an association. Lancet 1984;ii:768-70

20 Egan JJ, Stewart JP, Hasleton PS, et al. Epstein-Barr virus replication within pulmonary epithelial cells in cryptogenic fibrosing alveolitis. Thorax 1995;50:1234-39.

21 Egan JJ, Stewart JP, Hasleton PS, et al. EBV PCR (Raji I) in idiopathic pulmonary fibrosis and sarcoidosis. Am f Respir Crit Care Med 1997; 155:A315.

22 Wangoo A, Nicholson AG, Diss TC, et al. Cryptogenic fibrosing alveolitis does not appear to be associated with Epstein-Barr virus infection. Thorax 1996;51(suppl 3):A11.

23 Bitterman PB, Rennard SI, Keogh BA, et al. Familial idiopathic pulmonary fibrosis: evidence of lung inflammation in unaffected family members. N Engl F Med 1986;314: 1343-7.

24 Carrington CB, Gaensler EA, Coutu RE, et al. Natural history and treated course of usual and desquamative interstitial pneumonia. N Engl f Med 1978;298:801-9.

25 Katzenstein AL, Fiorelli RF. Non-specific interstitial pneumonia/fibrosis. Am f Surg Pathol 1994;18:136-47.

26 Hamman L, Rich AR. Acute diffuse interstitial fibrosis. Bulletin of the fohn Hopkins Hospital 1944;74:177-212.

27 Bjoraker JA, Ryu JH, Edwin MK, et al. Prognostic significance of histopathologic subsets in idiopathic pulmonary fibrosis. Am F Respir Crit Care Med 1998;157:199-203.

28 Crystal RG, Fulmer JD, Roberts WC, et al. Idiopathic pulmonary fibrosis: clinical, histological, radiographic, physiologic, scintigraphic, cytological and biochemical aspects. Ann Intern Med 1976;85:769-88.

29 Keogh BA, Crystal RG. Clinical significance of pulmonary function tests: pulmonary function testing in interstitial pulmonary disease; what does it tell us? Chest 1980;78:856-65.

30 Ruben M, Cherniack TV, Colby AF, et al. Correlation of structure and function in idiopathic pulmonary fibrosis. $\mathrm{Am}$ structure and function in idiopathic pulm

31 Doherty MJ, Pearson MG, Calverly PMA. Cryptogenic fibrosing alveolitis with normal lung evolumes. Thorax 1995;50:433P

32 Hanson D, Winterbauer RH, Kirtland SH, et al. Changes in pulmonary function test results after one year of therapy as predictors of survival in patients with idiopathic pulmonary fibrosis. Chest 1995;108:305-10.

33 Gay SE, Kazerooni EA, Toews GB, et al. Idiopathic pulmonary fibrosis. Predicting response to therapy and survival. Am f Respir Crit Care Med 1998;157:1063-72.

34 Wells AU, Hansell DM, Harrison NK, et al. Clearance of inhaled ${ }^{99 \mathrm{~m}} \mathrm{Tc}$-DPTA predicts the clinical course of fibrosing alveolitis. Eur Respir f 1993;6:797-802.

35 Epler GR, Mcloud TC, Gaensler EA, et al. Normal chest roentgenograms in chronic diffuse infiltrative lung disease. roentgenograms in chronic diffus

36 Orens JB, Kazerooni EA, Martinez FJ, et al. The sensitivity of high-resolution CT in detecting idiopathic pulmonary fibrosis proved by lung biopsy. A prospective study. Chest 1995;108:109-15.

37 Muller NL, Miller RR, Webb WR, et al. Fibrosing alveolitis: CT-pathologic correlation. Radiology 1986;160:585-8.

38 Wells AU, Hansell DM, Corrin B, et al. High resolution computed tomography as a predictor of lung histology in systemic sclerosis. Thorax 1992;47:738-42.

39 Muller N, Staples CA, Miller RR, et al. Disease activity in idiopathic pulmonary fibrosis: CT and pathologic correlation. Radiology 1987;165:731-4.

40 Remy-Jardin M, Giraud F, Remy J, et al. Importance of ground glass attenuation in chronic diffuse infiltrative lung disease: pathologic-CT correlation. Radiology 1993;189: 693-8.

41 Tung KT, Wells AU, Rubens MB, et al. Accuracy of the typical computed tomographic appearances of fibrosing alveolitis. Thorax 1993;48:334-8.

42 Mathieson JR, Mayo JR, Staples CA, et al. Chronic diffuse infiltrative lung disease: comparison of diagnostic accuracy of CT and chest radiography. Radiology 1989;171:111-6.

43 Wells AU, Rubens MB, Du Bois RM, et al. Serial CT in fibrosing alveolitis: prognostic significance of the initial pattern. AfR 1993;161:1159-65.

44 Hartman TE, Primack SL, Kang E, et al. Disease progression in usual interstitial pneumonia compared with desquamative interstitial pneumonia. Assessment with serial CT. Chest 1996;110:378-82.

45 Hansell DM, Wells AU. State of the art. CT evaluation of fibrosing alveolitis-applications and insights. $\mathcal{F}$ Thorac Imaging 1996;11:231-49.

46 Turner-Warwick M, Haslam PL. The value of serial bronchoalveolar lavages in assessing the clinical response of 
patients with cryptogenic fibrosing alveolitis. Am Rev Respir Dis 1987;135:26-34

47 Turner-Warwick M, Burrows B, Johnston A. Cryptogenic fibrosing alveolitis: response to corticosteroid treatment and its effect on survival. Thorax 1980;35:593-9.

48 Raghu G, Depaso WJ, Cain K, et al. Azathioprine combined with prednisolone in the treatment of idiopathic pulmonary fibrosis: a prospective double-blind, randomised placebocontrolled clinical trial. Am Rev Respir Dis 1991;144:291-6.

49 Johnston MA, Kwan S, Snell NJ, et al. Randomised controlled trial comparing prednisolone alone with cyclophosphacryptogenic fibrosing alveolitis. Thorax 1989;44:280-8.
50 Douglas WW, Ryu JH, Swensen SJ, et al. Colchicine versus prednisolone in the treatment of idiopathic pulmonary fibrosis. Am f Respir Crit Care Med 1998;158:220-25.

51 Trulock EP. State of the art. Lung transplantation. $A m$ f Respir Crit Care Med 1997;155:789-818.

Answers: true (T)/false (F)

1. (A) T, (B) F, (C) T, (D) T; 2. (A) T, (B) T, (C) T, (D) T; 3. (A) F, (B) T, (C) T, (D) F; 4. (A) T, (B) F, (C) T, (D) $\mathrm{T}$; 5. (A) F, (B) T, (C) F, (D) F; 6. (A) F, (B) T, (C) $\mathrm{T}$, (D) $\mathrm{T}$. 